\title{
Retrospective study on sequelae in traumatized permanent teeth
}

\author{
Fernanda Chiguti Yamashita ${ }^{1}$, Isolde Terezinha Santos Previdelli ${ }^{2}$, \\ Nair Narumi Orita Pavan ${ }^{1}$, Marcos Sérgio Endo ${ }^{1}$
}

Correspondence: Dr. Marcos Sérgio Endo

Email: marcossendo@gmail.com

\author{
'Department of Dentistry, State University of Maringá, \\ Maringá, Paraná, Brazil, \\ 2Department of Statistic, State University of Maringá \\ Maringá, Paraná, Brazil
}

\section{ABSTRACT}

Objective: This study aimed to identify possible associations of the presence or absence of posttrauma sequelae with the factors inherent to the traumatized tooth and treatment. Materials and Methods: This retrospective study was performed through the evaluation of records and radiographs of a center of reference for dental trauma between January 2008 and December 2014. The factors were analyzed and associated with posttrauma sequelae, such as pulp necrosis and root resorption. Statistical Analysis Used: A binomial logistic regression model was fit $(P<0.05)$. Results: In luxations, it was possible to observe $37 \%$ pulp necrosis, $16 \%$ inflammatory root resorption, and $8 \%$ replacement resorption. The binomial logistic regression revealed that male gender $(P=0.0392$, odds ratio $[\mathrm{OR}]=2.79)$, avulsion injury $(P=0.0009, \mathrm{OR}=12.27)$, and elapsed time $>16$ days between the time of trauma to the beginning of the endodontic treatment $(P=0.0450, \mathrm{OR}=7.53)$ showed a greater chance of presenting a posttrauma complication. Conclusions: Gender, type of injury, stage of root development, and time after trauma until the beginning of the endodontic intervention were related to the appearance of sequelae.

Key words: Dental pulp necrosis, dental trauma, tooth resorption

\section{INTRODUCTION}

Dental trauma is very common and has higher incidence in children and adolescents, ${ }^{[1]}$ representing a situation of urgency that includes physical and psychological issues. ${ }^{[2]}$ Epidemiological studies indicate that approximately one-third of children and a quarter of adolescents and adults experience some type of dental trauma throughout their lives. ${ }^{[3]}$

Dental trauma corresponds to a set of impacts that affect the teeth and their support structures. Luxation

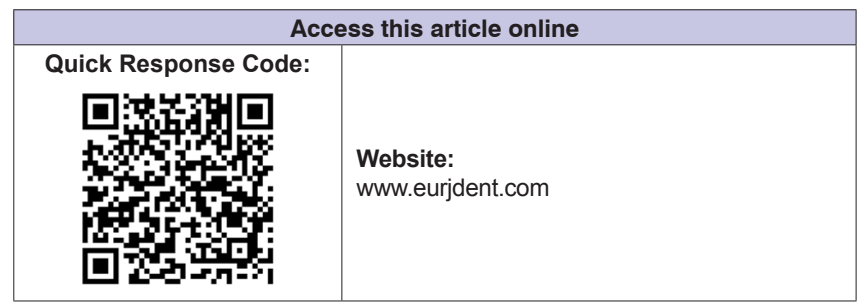

injury can result in damage to the set of periodontal structures, whose severity depends on the type of injury. ${ }^{[4]}$ During the follow-up period of traumatized teeth, some sequelae may be found, such as pulp necrosis, pulp cavity obliteration, and root and bone resorption. ${ }^{[5-7]}$

These complications may occur in weeks, months, or even years after the trauma ${ }^{[8]}$ and may be influenced by several factors, such as the degree of injury, time elapsed between dental trauma and endodontic

This is an open access article distributed under the terms of the Creative Commons Attribution-NonCommercial-ShareAlike 3.0 License, which allows others to remix, tweak, and build upon the work non-commercially, as long as the author is credited and the new creations are licensed under the identical terms.

For reprints contact: reprints@medknow.com

How to cite this article: Yamashita FC, Previdelli IT, Pavan NN, Endo MS. Retrospective study on sequelae in traumatized permanent teeth. Eur J Dent 2017;11:275-80.

DOI: 10.4103/ejd.ejd_85_17 
treatment, the stage of root development, type of splint and splinting time, the extraoral period of the dental element, or the storage medium of an avulsed tooth. ${ }^{[1,6,9-11]}$

Importantly, dental trauma has severe consequences, as it does not only impair the integrity of dentition, but it can also affect the individual's self-esteem and quality of life. The associations between posttrauma sequelae and involved factors in this sample universe have not yet been investigated; then it becomes important to know the profile of this population to contribute to this line of research and to improve the particular issues of this center of reference. In addition, from the results obtained, it will be possible to elaborate strategies to obtain a reliable collection of information and to draw up measures that allow the implementation of educational actions directed to the population, raising awareness of the occurrence of sequelae after dental trauma and the factors associated with prognosis. Thus, this study aimed to identify possible associations of the presence or absence of posttrauma sequelae with the factors inherent to the traumatized tooth and treatment.

\section{MATERIALS AND METHODS}

This research was approved by the Research Ethics Committee of the State University of Maringá (CAAE 53207716.5.0000.0104).

\section{Data collection}

This retrospective and cross-sectional study was conducted by means of the evaluation of dental records and radiographic examinations of a center of reference for dental trauma in the city of Maringá, state of Paraná, the project of extension Specialized Center of Dental Trauma of Maringá (CEMTrau/Odonto), at the State University of Maringá between January 2008 and December 2014. The demographic data of interest were: gender, age of the patient at the moment of traumatic injury, tooth affected, and cause and type of traumatic injury. Information regarding the root development stage, extra-alveolar time and storage medium of an avulsed tooth, type of splint and splinting time, intracanal medication, pulp necrosis, and root resorption were also collected [Table 1]. The information contained in the records along with the periapical radiographs were analyzed by an evaluator, using a magnifying glass and negatoscope.

Injuries to hard tissues and alveolar bone, root and crown-root fractures, teeth that had already undergone endodontic treatment, avulsed teeth that were not reimplanted, patients who did not complete the treatment, follow-up of $<1$ year in trauma with periodontal damage, dental records with no radiographs, and no information about the trauma were excluded from the study.

\begin{tabular}{|c|c|}
\hline Variables & Subdivisions of variables \\
\hline Gender & Male, female \\
\hline Age & I: 6-11, II: 12-17, III: 18-56 \\
\hline Stage of root development & I: Open apex, II: Closed apex \\
\hline Type of injury & $\begin{array}{l}\text { Concussion, subluxation, lateral luxation, intrusive } \\
\text { luxation, extrusive luxation, avulsion }\end{array}$ \\
\hline Cause of injury & $\begin{array}{l}\text { Car accident, motorcycle accident, physical } \\
\text { aggression, run over, bicycle, fall, pool, sports }\end{array}$ \\
\hline Tooth location & $11,12,13,14,21,22,23,24,31,32,33,41,42,43$ \\
\hline Splint type & I: Rigid, II: Flexible \\
\hline Splinting time & I: Did not use, II: $<4$ days, III: $15-28$ days, IV: $>28$ days \\
\hline Extra-alveolar time of the avulsed tooth & $\mathrm{I}:<60 \min , \mathrm{II}: \geq 60 \min$ \\
\hline Storage medium of the avulsed tooth & Dry, milk, saline, saliva, water \\
\hline Time elapsed between dental trauma and endodontic treatment & I: No endodontic treatment, II: $\leq 5$ days, III: $16-28$ days, IV: $>28$ days \\
\hline Intracanal medication & Formocresol, calcium hydroxide, formocresol + calcium hydroxide \\
\hline Duration of intracanal medication & $\begin{array}{l}0: \text { No endodontic treatment, I: }<30 \text { days, II: } 31- \\
180 \text { days, III: } 181-365 \text { days, IV: }>365 \text { days }\end{array}$ \\
\hline PN & 0: Absence I: Presence \\
\hline IR & 0: Absence I: Presence \\
\hline $\mathrm{RR}$ & 0: Absence I: Presence \\
\hline Sequelae (PN, IR, RR) & 0: Absence I: Presence \\
\hline
\end{tabular}

PN: Pulp necrosis, IR: Inflammatory resorption, RR: Replacement resorption 


\section{Classification of variables}

The stage of root development was determined through the evaluation of periapical radiographs of the initial examination. Teeth were divided into two groups: open and closed apex. ${ }^{[12,13]}$

The time elapsed between the trauma and theendodontic treatment, the duration of intracanal medication, and the splinting time were evaluated in days. ${ }^{[14,15]}$ The extra-alveolar period was classified according to the time that is considered critical for the survival of periodontal ligament cells: less than $60 \mathrm{~min}$ and $\geq 60 \mathrm{~min} \cdot{ }^{[15]}$

\section{Diagnosis of posttrauma sequelae}

Diagnosis of pulp necrosis was based on the following clinical and radiographic criteria: the absence of pulp sensitivity through thermal pulp testing, crown color change, apical radiolucency, presence of fistula, or no painful response in the cavity test. ${ }^{[16,17]}$

The inflammatory root resorption was evidenced by the radiolucency adjacent to the bone tissue. ${ }^{[18]} \mathrm{In}$ turn, the replacement resorption was diagnosed by the loss of dental tissue of the root with consequent substitution by bone tissue and loss of the periodontal ligament and by a metallic sound when the tooth was submitted to vertical percussion [Figure 1] ${ }^{[6]}$

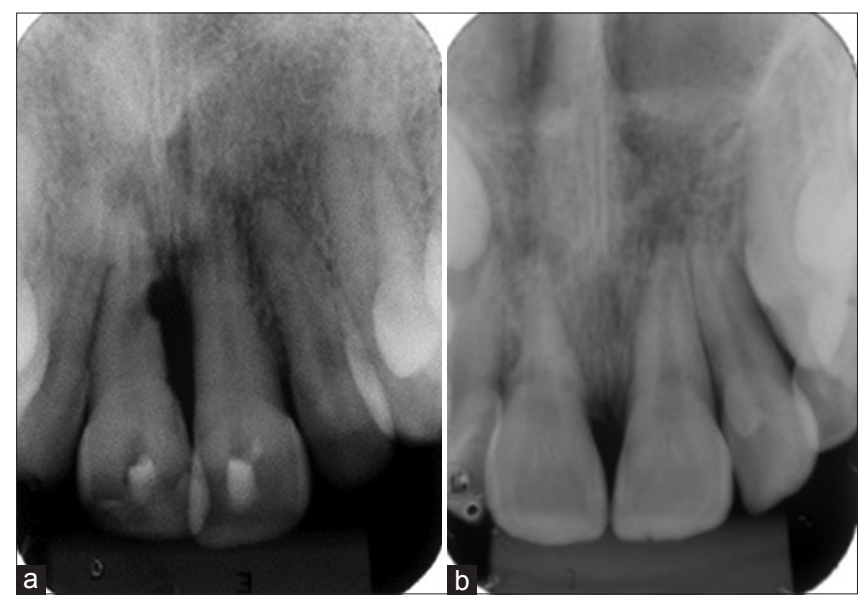

Figure 1: Root resorption. (a) Inflammatory root resorption (b) replacement resorption

\section{Statistical analysis}

The aim of the study was to identify the factors that determine the presence and absence of pulp necrosis, inflammatory root resorption, and replacement resorption; however, due to the small number of cases observed in the categories of variables, a variable response of interest was regrouped in the presence and absence of posttrauma sequelae. Thus, multivariate logistic regression was adopted to determine odds ratios (OR). The criterion of selection and exclusion of the variables in the model was followed by the methodology of Hosmer et al., ${ }^{[19]}$ using a level of significance of $5 \%$. Data obtained and analyzed statistically using the statistical Software $R$ version 3.1.0 (R Development Core Team (2014), $\mathrm{R}$ : A Language and Environment for Statistical Computing. Vienna, Austria: the R Foundation for Statistical Computing. Available online at http:/ / www.R-project.org.

\section{RESULTS}

The present study surveyed 531 dental records of patients treated between January 2008 and December 2014, of which 461 were excluded from this study. The population of traumatisms with dental damages was composed of 70 patients, in which 145 teeth were examined.

Of the 145 teeth that suffered damage to the periodontal tissues, $50 \%$ presented some type of sequelae, including inflammatory root resorption $(16 \%)$, replacement resorption $(8 \%)$, and pulp necrosis (37\%) [Table 2].

The binomial logistic regression revealed that male and avulsion presented 2.79 and 7.53 times more chances, respectively, to exhibit a posttrauma sequel. The OR was also higher for teeth that took between 16 and 60 days (12.27 times more chance) and an elapsed time $>60$ days (21.71 times more chance) between trauma and endodontic treatment [Table 3].

Table 2: Frequency of sequelae according to the type of injury

\begin{tabular}{lcccc} 
& Total, $\boldsymbol{n}(\%)$ & Pulp necrosis, $\boldsymbol{n}(\%)$ & Inflammatory resorption, $\boldsymbol{n}$ (\%) & Replacement resorption, $\boldsymbol{n}(\%)$ \\
\hline Concussion & $5(3)$ & 0 & 0 & 0 \\
Subluxation & $14(10)$ & $2(14)$ & $1(7)$ & 0 \\
Extrusive luxation & $23(16)$ & $9(39)$ & $3(13)$ & $1(4)$ \\
Lateral luxation & $61(42)$ & $22(36)$ & $5(8)$ & $4(7)$ \\
Intrusive luxation & $9(6)$ & $3(33)$ & $1(11)$ & 0 \\
Avulsion & $33(23)$ & $17(52)$ & $13(39)$ & $6(18)$ \\
Total & $145(100)$ & $53(37)$ & $23(16)$ & $11(8)$ \\
\hline
\end{tabular}




\begin{tabular}{|c|c|c|c|c|c|}
\hline & Total, $n(\%)$ & Sequelae, $n_{1}(\%)$ & OR & $95 \% \mathrm{Cl}$ & $P$ \\
\hline \multicolumn{6}{|l|}{ Gender } \\
\hline Male & $89(66)$ & $53(62)$ & 2.79 & $1.07-7.69$ & 0.0392 \\
\hline \multicolumn{6}{|l|}{ Time elapsed (days) } \\
\hline$\leq 15$ & $13(9)$ & $9(69)$ & 3.77 & $0.74-22.37$ & 0.1159 \\
\hline $16-60$ & $25(17)$ & $22(88)$ & 12.27 & $3.08-64.80$ & 0.0009 \\
\hline$>60$ & $30(21)$ & $26(87)$ & 21.71 & $6.76-88.79$ & $1.85 \mathrm{e}-06$ \\
\hline \multicolumn{6}{|l|}{ Type of injury } \\
\hline Extrusive luxation & $23(16)$ & $10(43)$ & 1.42 & $0.23-10.42$ & 0.7245 \\
\hline Lateral luxation & $61(42)$ & $29(48)$ & 2.33 & $0.51-14.40$ & 0.3115 \\
\hline Intrusive luxation & $9(6)$ & $4(44)$ & 2.38 & $0.23-26.24$ & 0.4642 \\
\hline Avulsion & $33(23)$ & $27(82)$ & 7.53 & $1.07-63.21$ & 0.0450 \\
\hline
\end{tabular}

\section{DISCUSSION}

Dental trauma involves the hard tissues and pulp, gingiva and/or oral mucosa, periodontal ligament, cementum, and bone tissue, ${ }^{[20]}$ and the survival of the traumatized tooth will depend on factors related to the tooth/patient (gender, type of injury, and stage of root development), posttrauma care by the patient (storage medium and extra-alveolar period of an avulsed tooth) and also the treatment chosen after trauma (time elapsed between dental trauma and endodontic treatment, type of splint and splinting time, intracanal medication, and time using this medication). ${ }^{[9,11,15]}$

Posttraumatic complications were found in 73 teeth (50\%), in which pulp necrosis was the most common. ${ }^{[5,21]}$ Mild luxation, such as concussion and subluxation, presented few complications, corroborating previous studies, ${ }^{[7,13]}$ and studies have revealed that tooth crown fractures concomitant with these luxations increase the risk of pulp necrosis. ${ }^{[22,23]}$ On the other hand, lateral and extrusive luxations showed a better prognosis than more severe luxation but with few cases of root resorption. ${ }^{[24,25]}$

Intrusion is a severe injury, as it promotes the crushing of fibers of the periodontal ligament, causes a lesion in the bone tissue and cementum and disrupts the neurovascular supply. Therefore, the repair process may be accompanied by a series of posttrauma complications and the occurrence of pulp necrosis is inevitable. ${ }^{[20]}$ According to some studies, the frequency of complications varies from $85 \%$ to $100 \%$ and is related to the root development. ${ }^{[8,9]}$ Despite this, Humphrey et al. ${ }^{[12]}$ reported a lower frequency of pulp necrosis (45\%), in which the majority of the teeth (58\%) had open apex, which is consistent with the findings of this study that observed a frequency of $33 \%$ in teeth with intrusive luxation. Intruded teeth also presented a low frequency of inflammatory root resorption $(11 \%)$ and no replacement resorption. In general, 4 teeth $(44 \%)$ had posttrauma sequelae and 5 teeth $(56 \%)$ had not. This low frequency of complications in relation to intruded teeth can be related to the open apex at the time of the trauma ${ }^{[9,26]}$ and the size of the sample $(n=9)$, which may be related to the late treatment demand since many patients initially go to the hospital. Thus, in this period, there is spontaneous eruption of the intruded tooth, which reduces the number of intrusions.

Avulsion was the injury that showed more sequelae $(82 \%)$, contributing with $52 \%$ pulp necrosis, 39\% inflammatory root resorption, and $18 \%$ replacement resorption [Table 2]. For a clinical approach, considering the presence of all variables evaluated, a binomial logistic regression model was run. In Table 3, it was observed that the avulsion was associated with 7.53-fold increase in the odds of obtaining a complication in comparison to the baseline subluxation (OR: 7.53; confidence interval [CI]: 1.07-63.21). In the test in question, the avulsion was not compared to the concussion because the number of cases was very small $(n=5)$. This small number of cases of concussion can be attributed to the fact that clinically there is no change in a tooth that has suffered concussion, in this way it is common for the patient not to seek immediate care, which also implies an underdiagnosis by the dentist.

The results of this study confirmed that being male is a predisposing factor to the occurrence of dental injuries $^{[2]}$ and consequently to the appearance of complications. In addition to avulsion and males, binomial logistic regression revealed that the time elapsed between all luxations $>16$ days between the 
time of trauma and the beginning of endodontic treatment presented a greater chance of presenting a complication (OR: 12.27, CI: 3.08-64.80), as well as when the time is $>60$ days (OR: 21.71; CI: 6.76-88.79). Consistent with our results, Hinckfuss and Messer ${ }^{[14]}$ in a meta-analysis concluded that periodontal healing is improved with pulp extirpation within 14 days. In addition, a late pulp extirpation, beyond 3 weeks, is related to a high frequency of inflammatory root resorption. ${ }^{[1,27]}$

Currently, in cases with indication of endodontic treatment, the optimal time to initiate treatment in avulsed teeth is $7-10$ days ${ }^{[15,28]}$ and to minimize or prevent an inflammatory resorption, an early extirpation of the pulp should be performed. [29] Nevertheless, in teeth with open apex, endodontic treatment may be postponed, as it is possible that revascularization of the pulp occurs. ${ }^{[15]}$

Reasons inherent to the patient, such as incomplete information about the history of the trauma, seek care late, discontinuation of treatment, and the failure to accurately fill the records on the factors relevant to trauma represent a limitation of observational studies. The lack of commitment of the patient to the periodic follow-up of these injuries could be experienced in this study, which is not reported in retrospective studies. ${ }^{[7,26]}$ This follow-up is essential for the early diagnosis of complications subsequent to the trauma. ${ }^{[5,8]}$ In this sense, it is suggested educational actions ${ }^{[30]}$ aimed at the population on posttrauma complications and related factors, as well as the improvement of the data collection system, such as the use of electronic records, photographic documentation, and the use of digital radiographs for better follow-up in the long term.

\section{CONCLUSIONS}

Considering the methodology proposed and limitations of this study, we conclude that: bearing in mind that dental trauma is a dynamic and multifactorial aspect, which involves countless variables, male patients, avulsion injury, and time elapsed between dental trauma and the beginning of endodontic treatment $>16$ days presented a higher chance for the occurrence of sequelae.

\section{Financial support and sponsorship}

Nil.

\section{Conflicts of interest}

There are no conflicts of interest.

\section{REFERENCES}

1. Kinirons MJ, Boyd DH, Gregg TA. Inflammatory and replacement resorption in reimplanted permanent incisor teeth: A study of the characteristics of 84 teeth. Endod Dent Traumatol 1999;15:269-72.

2. Cortes MI, Marcenes W, Sheiham A. Impact of traumatic injuries to the permanent teeth on the oral health-related quality of life in 12-14-year-old children. Community Dent Oral Epidemiol 2002;30:193-8.

3. Lam R. Epidemiology and outcomes of traumatic dental injuries: A review of the literature. Aust Dent J 2016;61 Suppl 1:4-20.

4. Breik O. Discuss how the management of trauma to the dentition is influenced by the type and severity of injury. Aust Endod J 2008;34:120-5.

5. Andreasen JO. Luxation of permanent teeth due to trauma. A clinical and radiographic follow-up study of 189 injured teeth. Scand J Dent Res 1970;78:273-86.

6. Al-Badri S, Kinirons M, Cole B, Welbury R. Factors affecting resorption in traumatically intruded permanent incisors in children. Dent Traumatol 2002;18:73-6.

7. Hecova H, Tzigkounakis V, Merglova V, Netolicky J. A retrospective study of 889 injured permanent teeth. Dent Traumatol 2010;26:466-75.

8. Andreasen FM, Pedersen BV. Prognosis of luxated permanent teeth-the development of pulp necrosis. Endod Dent Traumatol 1985;1:207-20.

9. Andreasen JO, Bakland LK, Andreasen FM. Traumatic intrusion of permanent teeth. Part 2. A clinical study of the effect of preinjury and injury factors, such as sex, age, stage of root development, tooth location, and extent of injury including number of intruded teeth on 140 intruded permanent teeth. Dent Traumatol 2006;22:90-8.

10. Petrovic B, Markovic D, Peric T, Blagojevic D. Factors related to treatment and outcomes of avulsed teeth. Dent Traumatol 2010;26:52-9.

11. Bastos JV, Ilma de Souza Côrtes M, Andrade Goulart EM, Colosimo EA Gomez RS, Dutra WO. Age and timing of pulp extirpation as major factors associated with inflammatory root resorption in replanted permanent teeth. J Endod 2014;40:366-71.

12. Humphrey JM, Kenny DJ, Barrett EJ Clinical outcomes for permanent incisor luxations in a pediatric population. I. Intrusions. Dent Traumatol 2003;19:266-73.

13. Hermann NV, Lauridsen E, Ahrensburg SS, Gerds TA, Andreasen JO. Periodontal healing complications following concussion and subluxation injuries in the permanent dentition: A longitudinal cohort study. Dent Traumatol 2012;28:386-93.

14. Hinckfuss SE, Messer LB. An evidence-based assessment of the clinical guidelines for replanted avulsed teeth. Part I: Timing of pulp extirpation. Dent Traumatol 2009;25:32-42.

15. Andersson L, Andreasen JO, Day P, Heithersay G, Trope M, Diangelis AJ, et al. International association of dental traumatology guidelines for the management of traumatic dental injuries: 2 . Avulsion of permanent teeth. Dent Traumatol 2012;28:88-96.

16. Jacobsen I. Criteria for diagnosis of pulp necrosis in traumatized permanent incisors. Scand J Dent Res 1980;88:306-12.

17. Andreasen FM, Zhijie Y, Thomsen BL. Relationship between pulp dimensions and development of pulp necrosis after luxation injuries in the permanent dentition. Endod Dent Traumatol 1986;2:90-8.

18. Tronstad L. Root resorption-etiology, terminology and clinical manifestations. Endod Dent Traumatol 1988;4:241-52.

19. Hosmer DW, Lemeshow S, Sturdivant RX. Applied Logistic Regression. $3^{\text {rd }}$ ed. New Jersey: John Wiley \& Sons; 2013.

20. Andreasen JO, Andreasen FM. Texto e Atlas Colorido de Traumatismo Dental. $3^{\text {rd }}$ ed. São Paulo: Artmed Editora; 2001.

21. Sandalli N, Cildir S, Guler N. Clinical investigation of traumatic injuries in Yeditepe University, Turkey during the last 3 years. Dent Traumatol 2005;21:188-94.

22. Lauridsen E, Hermann NV, Gerds TA, Ahrensburg SS, Kreiborg S, Andreasen JO. Combination injuries 1. The risk of pulp necrosis in permanent teeth with concussion injuries and concomitant crown fractures. Dent Traumatol 2012;28:364-70.

23. Lauridsen E, Hermann NV, Gerds TA, Ahrensburg SS, Kreiborg S, Andreasen JO. Combination injuries 2. The risk of pulp necrosis in permanent teeth with subluxation injuries and concomitant crown fractures. Dent Traumatol 2012;28:371-8.

24. Lee R, Barrett EJ, Kenny DJ. Clinical outcomes for permanent incisor luxations in a pediatric population. II. Extrusions. Dent Traumatol 
2003;19:274-9.

25. Ferrazzini Pozzi EC, von Arx T. Pulp and periodontal healing of laterally luxated permanent teeth: Results after 4 years. Dent Traumatol 2008;24:658-62.

26. Tsilingaridis G, Malmgren B, Andreasen JO, Wigen TI, Maseng Aas AL, Malmgren $\mathrm{O}$, et al. Scandinavian multicenter study on the treatment of 168 patients with 230 intruded permanent teeth-a retrospective cohort study. Dent Traumatol 2016;32:353-60.

27. Andersson L, Bodin I. Avulsed human teeth replanted within 15 minutes-a long-term clinical follow-up study. Endod Dent Traumatol 1990;6:37-42
28. American Association of Endodontics. Recommended Guidelines of the American Association of Endodontists for the Treatment of Traumatic Dental Injuries. Chicago; 2013. Available from: http://www. nxtbook.com/nxtbooks/aae/traumaguidelines. [Last accessed on 2016 Oct 08].

29. Kling M, Cvek M, Mejare I. Rate and predictability of pulp revascularization in therapeutically reimplanted permanent incisors. Endod Dent Traumatol 1986;2:83-9.

30. Ozer S, Yilmaz EI, Bayrak S, Tunc ES. Parental knowledge and attitudes regarding the emergency treatment of avulsed permanent teeth. Eur J Dent 2012;6:370-5. 